\title{
Design of a Sea-level Tsunami Detection Network for the Gulf of Cadiz
}

\author{
R. Omira ${ }^{1,2}$, M. A. Baptista ${ }^{1,3}$, L. Matias ${ }^{1,4}$, J. M. Miranda ${ }^{1}$, C. Catita ${ }^{1}$, F. Carrilho ${ }^{4}$, and E. Toto ${ }^{2}$ \\ ${ }^{1}$ University of Lisbon, CGUL, IDL, Lisbon, Portugal \\ ${ }^{2}$ University Ibn Tofail, Faculty of Sciences, Kénitra, Morocco \\ ${ }^{3}$ Instituto Superior de Engenharia de Lisboa, Portugal \\ ${ }^{4}$ Instituto de Meteorologia, Lisbon, Portugal
}

Received: 26 February 2009 - Revised: 25 June 2009 - Accepted: 19 July 2009 - Published: 31 July 2009

\begin{abstract}
The devastating impact of the Sumatra tsunami of 26 December 2004, raised the question for scientists of how to forecast a tsunami threat. In 2005, the IOCUNESCO XXIII assembly decided to implement a global tsunami warning system to cover the regions that were not yet protected, namely the Indian Ocean, the Caribbean and the North East Atlantic, the Mediterranean and connected seas (the NEAM region). Within NEAM, the Gulf of Cadiz is the more sensitive area, with an important record of devastating historical events. The objective of this paper is to present a preliminary design for a reliable tsunami detection network for the Gulf of Cadiz, based on a network of sealevel observatories. The tsunamigenic potential of this region has been revised in order to define the active tectonic structures. Tsunami hydrodynamic modeling and GIS technology have been used to identify the appropriate locations for the minimum number of sea-level stations. Results show that 3 tsunameters are required as the minimum number of stations necessary to assure an acceptable protection to the large coastal population in the Gulf of Cadiz. In addition, 29 tide gauge stations could be necessary to fully assess the effects of a tsunami along the affected coasts of Portugal, Spain and Morocco.
\end{abstract}

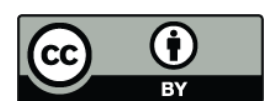

Correspondence to: R. Omira (omirarachid10@yahoo.fr)

\section{Introduction}

Since the Boxing Day tsunami of 2004 (Mw=9.3), the disaster, which caused more than 250000 deaths, there has been an increased awareness of the threat posed by tsunami waves. Scientists, supported by governmental and humanitarian organizations, have been mobilized to find a way to protect and warn the endangered populations. As a result, the number of tsunami monitoring stations around the world is increasing. The Intergovernmental Oceanographic Commission (IOC) of UNESCO, by its XXIII-14 resolution, decided to establish an Intergovernmental Coordination Group to implement a tsunami warning system (TWS) for the North East Atlantic, Mediterranean and connected seas (ICG/NEAMTWS).

In the Pacific Ocean, the TWS has been in place since 1965. Today, the system utilizes a network of seismic stations and another network of coastal gauges and tsunameters (DART (Deep-ocean Assessment and Reporting of Tsunamis) sensors, or cable ocean bottom stations) to detect tsunami waves. Following the catastrophic tsunami event of 26 December 2004, the construction of a TWS was initiated in the Indian Oceans with the enhancement of the seismic and sea-level networks, in particular the deployment of 5 tsunameters off West Sumatra and South Java, and tens of new tide gauges and seismic stations. This system was officially launched recently by the Indonesian authorities. Since 2005, the Indian Ocean and Caribbean regions have been covered by interim systems, which were provided by PTWC (Pacific Tsunami Warning Center) (Indian Ocean and Caribbean), JMA (Japan Meteorological Agency) (Indian Ocean) and WC/ATWC (West Coast/Alaska Tsunami Warning Center) (Gulf and North-West Atlantic). The NEAM region remains today as the only area of the world that has not yet been covered by any type of TWS.

Published by Copernicus Publications on behalf of the European Geosciences Union. 
Tsunamis are considered a major risk in the Gulf of Cadiz, due to the peculiar geological context (i.e., at the western end of the Nubia-Eurasia plate boundary), and also the high coastal vulnerability. The extensive occupation of coastal areas in the surrounding countries (Portugal, Spain and Morocco), the enormous influx of tourists during high season and the large economic value of harbors and other coastal facilities increase considerably the vulnerability to tsunami impact in this region. This region has been the place of several tsunamis, like the well-known event of 1 November 1755 (Baptista et al., 1998a, b). Other smaller tsunamis were recorded in the area during the 20th century on the 25 November 1941, 28 February 1969 and 26 May 1975. The analysis of the 1969 tsunami event was presented in former studies (Baptista et al., 1992; Heinrich et al., 1994; Gjevik et al., 1997). The recent revision of the Portuguese tsunami catalogue (Baptista and Miranda, 2009) presented the only witness observations of the waves arriving in land. At least a dataset of 13 tide records were obtained and processed in order to locate the tsunami source (Gjevik et al., 1997). The strongest amplitude was observed at the tide station of Casablanca, Morocco and significant tsunami amplitudes were recorded in Cascais (close to Lisbon) and Faro, Portugal. Therefore, development of a TWS for the Gulf of Cadiz is imperative, not only for regional, but also for local tsunami threat. The implementation of a TWS can considerably decrease the number of lives lost if a tsunami occurs.

All TWSs that have been developed to the present detect only those tsunamis that are caused by large magnitude earthquakes and so their operation must rely firstly on an effective seismic network operation. For tsunami sources close to the coast the seismic network must provide information on location and moment magnitude 5 min after the onset of the earthquake, at the least. JMA, relying on a dense seismic network and a mostly automatic system can provide this information for the Japanese coasts as soon as $1.5 \mathrm{~min}$ after the onset of the earthquake (H. Mikada, personal communication, 2008). These seismic parameters trigger the first message from the TWS to the civil protection authorities by applying a decision matrix that has been defined previously based on historical and past information, complemented by hydrodynamic modeling.

The degree of certainty of the first information is quite low, since it is known that only a few of the large magnitude earthquakes do, indeed, generate tsunamis. In order to be effective, the TWS must confirm that a tsunami has been generated or not, and measure its wave height. To accomplish this, the TWS must observe in real-time the sea-level disturbances that have been generated by the propagating waves of the tsunami. The commonest and simplest observations are those that are made at coastal tide-gauges, but they do not provide advance warning for the coastal areas that are close to tsunamigenic sources. In order to provide full coverage to the affected coasts, the TWS must detect and observe the tsunami in deep water, long before the waves reach the shore.
In summary, the assessment of tsunami hazards by decision-makers at Tsunami Warning Centers (TWC) requires collection and interpretation of precise data related to tsunamis generation, propagation and impact on coastlines. An effective TWS must consist of two main observation and analysis networks: (i) a seismological network to evaluate the parameters of potential tsunamigenic earthquakes, (ii) sea level observations by coastal and deep water tide gauges (tsunameters) to confirm the occurrence of a tsunami.

Previously, to design the installation of the TWS, extensive studies of the seismic potential of the area were needed to evaluate the locations and generation mechanism for the earthquake sources capable of generating destructive tsunamis. This information helps to specify tsunami generation scenarios. Also crucial is knowledge of deep ocean tsunami dynamics, the tsunami time of arrival at the at-risk coasts and the near-shore tsunami waveform for the tsunami scenarios.

Recent studies have addressed the problem of how to deploy tsunameters in an effective way to detect tsunamis generated by different source lengths assuring adequate coverage (Gonzalez et al., 2005; Schindelé et al., 2008). These studies propose equally spaced tsunameters' networks for different regions: the Pacific and the Eastern Mediterranean area. Gonzales et al. (2005) have proposed a network of 25 to 50 tsunameters to cover the known tsunamigenic zones in the Pacific of about $9000 \mathrm{~km}$ in length. Their strategy is based on the consideration that a tsunameters spacing of $200-400 \mathrm{~km}$ is required to assess the energy beam of a M8 tsunami event. More recently, Schindelé et al. (2008) have presented a design of a sea-level monitoring network for the Western Mediterranean basin. They have considered the whole North African coast as a continuous seismic region of approximately $1500 \mathrm{~km}$ in length and proposed a network of 13 tsunameters with a spacing of $50-90 \mathrm{~km}$ located around $50 \mathrm{~km}$ away the shoreline. However, in the Gulf of Cadiz area, no large continuous tsunamigenic region, similar to those considered in the previous studies, can be considered. Therefore, only a methodology that takes into account the specificity of the tsunamigenic potential in the Gulf of Cadiz area can provide a reliable tsunami detection network for such region.

This study seeks to present the steps necessary to establish an effective tsunami warning system in the Gulf of Cadiz. The TWS design process begins with an assessment of the tsunamigenic potential in the region by identifying the active tectonic structures. It is completed by the design of a sealevel detection network based on numerical computations of deep ocean tsunami dynamics and GIS technologies. The study adopts a specific strategy for the tsunameter installation based upon three main criteria: (i) the maximization of advance warning time, (ii) the coverage of all of the area where a tsunami could be generated and, finally, (iii) the installation conditions. The latter include flat bottom topography and the "safe" distance of station location from the 
seismic source. These criteria are proposed to control the assessment of the optimal tsunameters' locations in order to maximize the warning time and minimize the sensors number. Moreover, additional coastal tide gauge stations are recommended in site-specific of major tsunami impact and minimum tsunami travel time.

\section{Tsunamigenic earthquake potential in the Gulf of Cadiz}

To forecast future tsunamigenic earthquakes in the Gulf of Cadiz area, it is necessary to first define the seismogenic scenarios, as well as the associated fault parameters. The approach that we choose was to gather the best information available in order to establish the main seismic active features. We consider all positive identifications of significant neotectonic submarine structures and re-evaluate all scenarios presented up to now to temptatively explain the seismic and tsunami observations of historical events known to stroke the Portuguese, Spanish and Morocco coasts. Coarse segmentations of the potential tsunamigenic source zones (TSZs) were designed. The Maximum Credible Earthquake (MCE) and the associated Typical Fault (TF) were defined for each zone. TFs to be considered for each SZ should (i) have been positively identified by seismo-stratigraphic research or at least deduced from morphostructural analysis of swath bathymetry data; (ii) provide a clear indication of quaternary activity or (iii) have been deduced from instrumental seismic data.

The Gulf of Cadiz developed as a result of the interaction between the southern end of the Iberia palaeo-margin, the westward displacement of the Gibraltar arc, and the convergence of the African and Eurasian plates. Since the upper Miocene period, the collision between the African and Eurasian plates has caused a compression in the N-NW direction (Zühlke et al., 2004). At the same time, the Alboran domain migrated towards the west forming the Betic-Riffean orogenic belt, and forming the Gibraltar arc, thrusting over the continental margins of Iberia and Africa. This emplacement of the orogenic front caused a series of overthrusted allochthonous wedges over the eastern part of the Gulf of Cadiz. These allochthonous units were later reactivated and new wedges were emplaced successively in the central and western parts of the Gulf of Cadiz by a combined mechanism of mass gravity sliding and collapse along the slope, and later reactivated tectonically due to the N-NW convergence (Medialdea et al., 2004). These two tectonic mechanisms imply two different structural behaviors in the Gulf of Cadiz: (1) in the eastern part, from the Horseshoe Abyssal Plain towards the Gibraltar Arc, a mixture of thin-skinned and thickskinned tectonics comprising westward thrusting of the upper sedimentary units and the whole crust, respectively, and (2) in the western part, towards the Gorringe Bank and Coral Patch, thick skinned tectonics compressing the whole crust

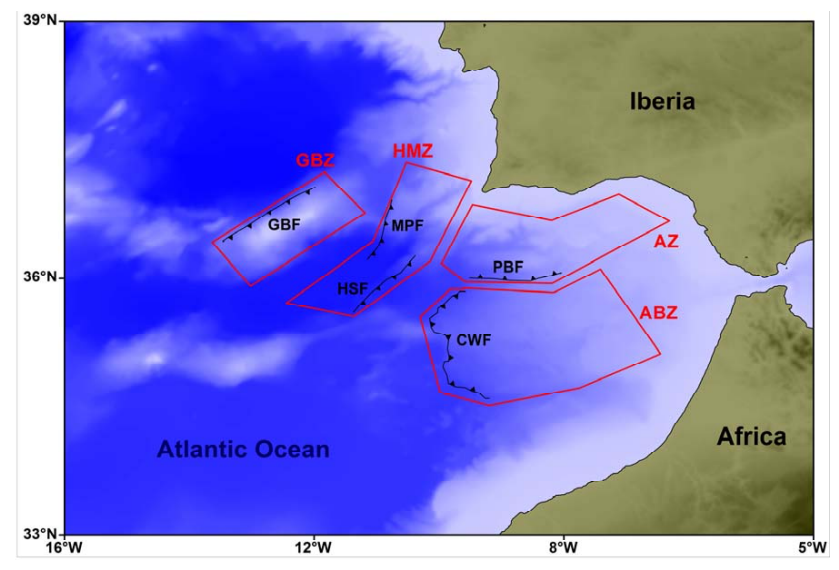

Fig. 1. Potential tsunamigenic source zones and the corresponding typical faults in the Gulf of Cadiz region. Source zones (red polygons); GBZ: Gorringe bank zone; HMZ: Horseshoe/Marques de Pombal zone; AZ: South Algarve zone and ABZ: Alboran wedge Slab zone. Typical faults (black traces); GBF: Gorring Bank fault; MPF: Marques de Pombal fault, HSF: Horseshoe fault, PBF: Portimao Bank fault and CWF: Cadiz Wedge fault.

and, possibly, the upper mantle too (Stich et al., 2005), by means of high-angle reverse faults (Medialdea et al., 2004; Iribarren et al., 2007).

Most damaging earthquakes and tsunamis that have affected the coasts of Portugal, Morocco and Spain were probably generated in the SWIT (SW Iberian Transpressive Domain) zone. Within the SWIT, four individual TSZs have been identified (Fig. 1). They are the Gorringe Bank (GBZ), the Horseshoe/Marques de Pombal (HMZ), the South Algarve (AZ) and the Alboran wedge Slab (ABZ). Five typical faults have been identified within the four source zones. They are: the Gorringe Bank fault (GBF) (Johnston, 1996), the Marques de Pombal Fault (MPF) (Zitellini et al., 1999), the Horseshoe Fault (HSF) (Gràcia et al., 2003; Matias et al., 2005), the Portimao Bank Fault (PBF) (Baptista et al., 2003) and the Cadiz Wedge Fault (CWF) (Gutscher et al., 2002, 2006). Their locations are specified in Fig. 1. In each source zone a Maximum Credible Earthquake (MCE) was designed. This MCE was associated with a typical fault in each source, generating the maximum credible tsunami scenario for each fault. Compared to tsunamigenic faults that have been identified by geological studies in the region of the Gulf of Cadiz, the dimensions of TFs that are considered in this study have been extended in order to be in agreement with the magnitude attributed to the corresponding MCE. To obtain the slip magnitude, the scaling relationship of Scholz (1982) that is based on fault lengths and Length/Width relations has been used. The sources, GBF, HSF and PBF are considered to be thrusts. Thus, we have used a fixed dip of $35^{\circ}$. The CWF source that correspond to the basis of an accretionary wedge is considered to have a minimum dip of $5^{\circ}$, in agreement with Gutscher et al. (2006). The dip for PBF source was obtained 

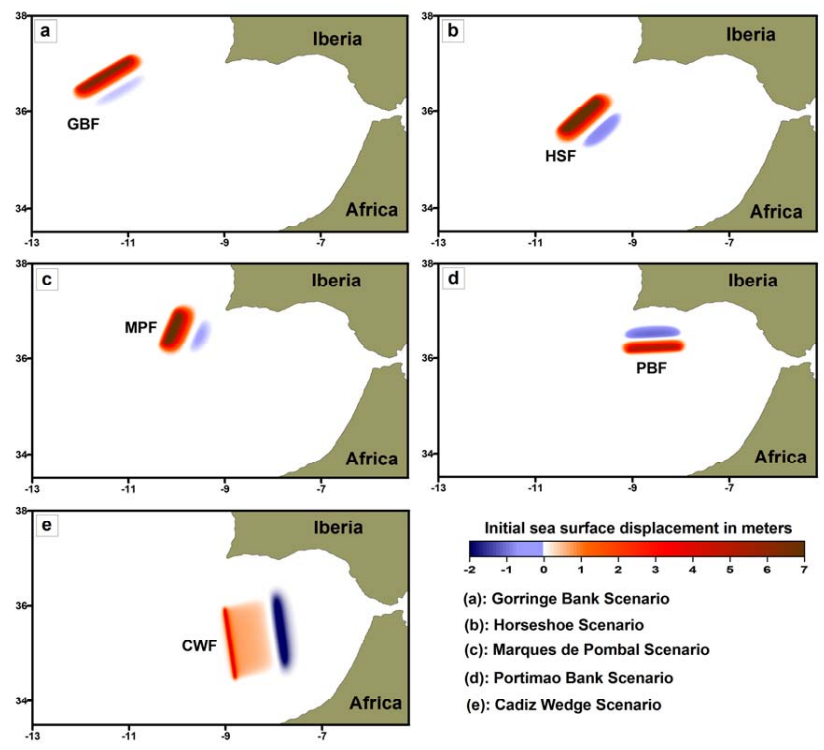

(a): Gorringe Bank Scenario

(b): Horseshoe Scenario

(c): Marques de Pombal Scenario

(d): Portimao Bank Scenario

(e): Cadiz Wedge Scenario

Fig. 2. Initial sea surface perturbation for each tsunami scenario in the Gulf of Cadiz; (a) Gorring Bank scenario, (b) Marques de Pombal scenario, (c) Horseshoe scenario, (d) Portimao Bank scenario, (e) Cadiz Wedge scenario.

from seismography studies (P. Terrinha, private communication, 2006). The fault characteristics for the worst tsunamigenic earthquake scenarios are specified in Table 1. The magnitude shown in Table 1 is obtained from the dimensions and slip of the fault following the seismic moment definition of Aki (1966) and the Mo-Mw relation defined by Kanamori and Anderson (1977).

\section{Tsunami hydrodynamic modeling}

\subsection{Maximum wave height computations}

Understanding how tsunamis are generated and propagated in the Gulf of Cadiz will help decision-makers in a TWS to determine how future tsunami disasters can be mitigated. In this study, the initial sea surface perturbation generated by the typical faults considered has been computed using the homogeneous half space elastic approach (Mansinha and Smiley, 1971; Okada, 1985).A discretized dip-directed slip distribution along the fault plane is adopted, following the smooth closure condition that is described in Geist and Dmowska (1999). For all candidate scenarios, the slip indicated in Table 1 corresponds to the average slip value. The source fault geometry has been simplified to a rectangle. Maximum wave heights (MWH) are computed for each tsunamigenic scenario in order to provide sitespecific predictions of tsunami impact on the Gulf of Cadiz coasts. The grid model for simulation of tsunami propagation, which corresponds to an $800 \mathrm{~m}$ resolution bathymetry grid of $1501 \times 1626$ grid-points, extends from $30^{\circ} \mathrm{N}$ to $42^{\circ} \mathrm{N}$ and from $4^{\circ} \mathrm{W}$ to $17^{\circ} \mathrm{W}$. The tsunami MWH calculation was done based on an adapted version of the Cornell Multigrid Coupled Tsunami Model (COMCOT) (Liu and Cho, 1994; Liu et al., 1995, 1998), which we have named COMCOT-Lx. The code uses an explicit leap-frog finite difference scheme to solve both linear and nonlinear shallow water equations on a dynamically coupled system of nested grids. Due to the fact that inundation and runup calculations are beyond the scope of this study (where non linear effects are important) we used the linear shallow water approximation and an $800 \mathrm{~m}$ resolution bathymetry grid without nesting. The time step used for tsunami simulations was $0.5 \mathrm{~s}$ and the computations were carried out for $7200 \mathrm{~s}$. The bathymetry model was generated from the GEBCO one-minute grid and bathymetric data from the SWIM compilation (Zitellini et al., 2009). Then the data were merged into a unique database and transformed to WGS84/UTM coordinates (fuse 29). The COMCOT-Lx version was benchmarked using Catalina Island Meeting case tests (3rd Workshop on Long-wave Runup Models, 2004). It was noted that the model reproduces good results for different benchmark tests \#1, \#2 and \#3. The code was also tested using the 28 February 1969 tsunami event as a benchmark case; the results obtained in form of wave amplitude and tsunami travel time were in good agreement with those presented in Heinrich et al. (1994) and Gjevik et al. (1997).

Figure 2a-e shows the computed initial sea surface displacements due to submarine earthquake scenarios. In spite of the scenarios' magnitude, which is relatively medium $\sim 8$, the initial sea surface displacement can be as high as $7 \mathrm{~m}$ for the average slip values listed in Table 1 . This is due to shallow rupture mechanisms and also the discretized slip distribution. The distributed slip affects the initial wave profile, giving a wave amplitude that is greater than that for a uniform slip distribution (Geist and Dmowska, 1999). It therefore affects the tsunami wave field away from the source region. Such effects are particularly important for local tsunamis, as it is the case in the Gulf of Cadiz, where the resulting tsunami runup is significantly affected by the initial wave profile (Geist and Dmowska, 1999). The established initial sea surface perturbations are used to generate the tsunami propagation and, then, to evaluate MWH distributions in the study region.

The results of MWH computations for each tsunamigenic scenario are presented in Fig. 3a-e. As expected, the tsunami amplitude at first order, is maximal in a direction perpendicular to the fault strike (Titov et al., 1999). For all source scenarios, except the Gorringe Bank one (scenario a), tsunami energy is steered toward the Gulf of Cadiz. However, different parameters, such as the fault orientation (strike angle) and the near-shore bathymetry control the distribution of tsunami energy along the shorelines. This is why MWH results show areas where the tsunami energy is less important (Lisbon and surrounding areas) than in others. In summary, it is evident from these results that the coasts in the study region are exposed to a major threat of tsunami. Coastal 
Table 1. Typical fault parameters of candidate tsunamigenic scenarios in the Gulf of Cadiz region. L: the fault length in kilometers; W: the fault width in kilometers; D: the depth from the sea bottom to the top of the fault in kilometers; $\mu$ : the shear modulus and $M_{w}$ : the moment magnitude.

\begin{tabular}{lllllllllllll}
\hline $\begin{array}{l}\text { Scenarios } \\
\text { name }\end{array}$ & $\begin{array}{l}\mathrm{L} \\
(\mathrm{km})\end{array}$ & $\begin{array}{l}\text { W } \\
(\mathrm{km})\end{array}$ & \multicolumn{2}{l}{$\begin{array}{l}\text { Epicenter coordinates } \\
\text { Lon }\end{array}$} & $\begin{array}{l}\text { Lat } \\
(\mathrm{km})\end{array}$ & $\begin{array}{l}\text { slip } \\
(\mathrm{m})\end{array}$ & $\begin{array}{l}\text { Strike } \\
\left({ }^{\circ}\right)\end{array}$ & $\begin{array}{l}\text { Dip } \\
\left({ }^{\circ}\right)\end{array}$ & $\begin{array}{l}\text { Rake } \\
\left({ }^{\circ}\right)\end{array}$ & $\begin{array}{l}\mu \\
(\mathrm{Pa})\end{array}$ & $\begin{array}{l}M_{w} \\
\text { Source } \\
\text { Zone }\end{array}$ \\
\hline GBF & 127 & 60 & -11.332 & 36.665 & 5.0 & 8.3 & 233.0 & 35 & 90 & $3.0 \times 10^{10}$ & 8.1 & $\mathrm{GBZ}$ \\
$\mathrm{HSF}$ & 165 & 70 & -9.913 & 35.796 & 4.0 & 10.7 & 42.1 & 35 & 90 & $3.0 \times 10^{10}$ & 8.3 & $\mathrm{HMZ}$ \\
$\mathrm{MPF}$ & 129 & 70 & -9.890 & 36.574 & 4.0 & 8.0 & 20.0 & 35 & 90 & $3.0 \times 10^{10}$ & 8.1 & $\mathrm{HMZ}$ \\
$\mathrm{PBF}$ & 105 & 55 & -8.585 & 36.314 & 2.5 & 7.2 & 266.3 & 24 & 90 & $3.0 \times 10^{10}$ & 8.0 & $\mathrm{AZ}$ \\
$\mathrm{CWF}$ & 168 & 200 & -8.059 & 35.407 & 5.0 & 10 & 349.0 & 5 & 90 & $3.0 \times 10^{10}$ & 8.6 & $\mathrm{ABZ}$ \\
\hline
\end{tabular}
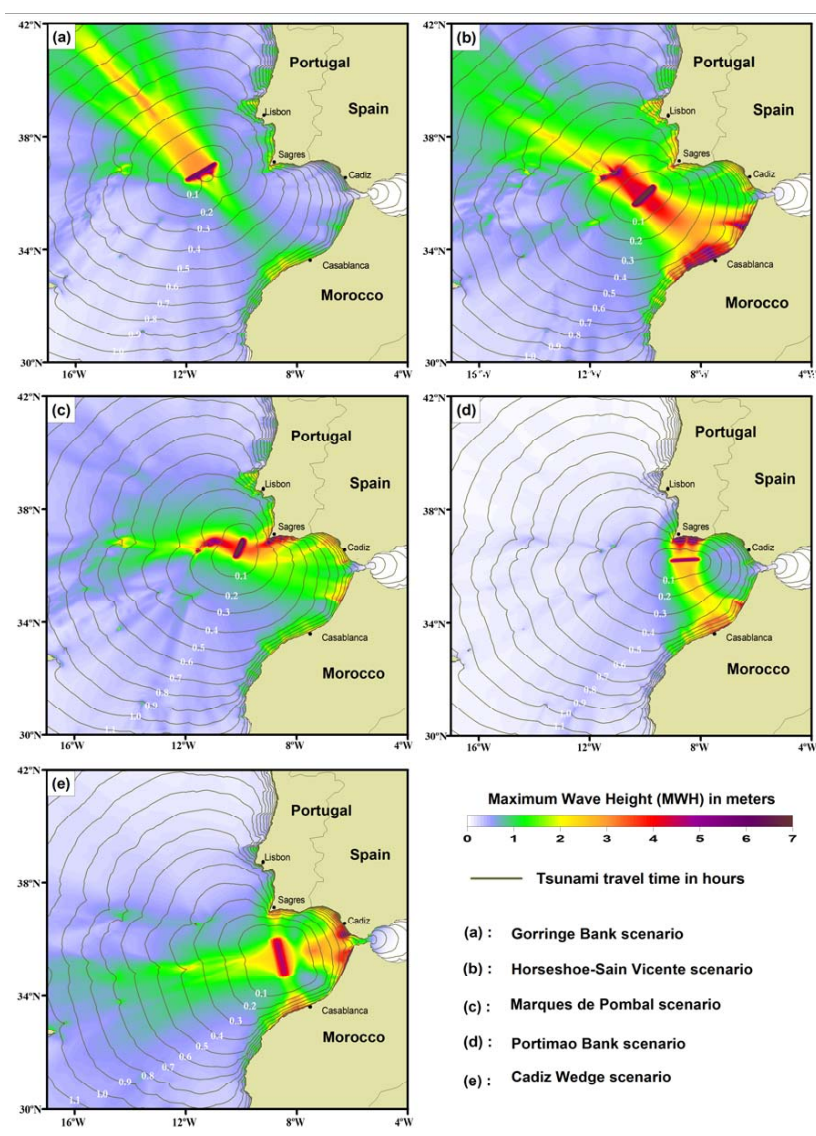

Fig. 3. Computed tsunami maximum wave height and travel time for different earthquake scenarios in the Gulf of Cadiz.

areas in the Gulf of Cadiz are characterized by heavy tourist and commercial activities, as well as important buildings and concentrations of population. All these factors make the region highly vulnerable to the impact of any tsunami. A 5-m tsunami wave could cause catastrophic loss of life in such an area, in the absence of a robust and fast TWS.

\subsection{Tsunami travel time, detection time and warning time estimations}

\subsubsection{Tsunami travel time estimation}

Tsunami forecasts should provide information about tsunamis well before the first wave strikes a threatened community. For this reason the estimation of the tsunami's arrival time constitutes an essential step when building a TWS. Here, the tsunami travel time (TTT) has been estimated using the ray tracing technique, which simulates the horizontal displacement of the sea surface perturbation using a linear long wave approximation. Such an approximation is the most appropriate for TWS because it gives a faster tsunami arrival time to a given shoreline and therefore it is suitable to forecast the worst case concerning the TTT.

The computed tsunami arrival times for the proposed tsunamigenic scenarios are presented in Fig. 3a-e. The time required for the first tsunami wave to reach the nearby coast is very short. The analysis of TTT-maps indicates that, for all scenarios, the Sagres coast (SW of Portugal) is the first point to be threatened by tsunami waves. Due to the local tsunami threat in the study area, the first wave arrives at the first shoreline in only few minutes after the occurrence of the quake 18 to $28 \mathrm{~min}$. In this study, we propose also to assess the error related to the estimation of the TTT. A comparison of the arrival times computed using linear and nonlinear approximations is presented. Scenario b (HSF) is considered to be the earthquake source and the harbor of Casablanca-Morocco is taken as the area for which both linear and nonlinear approximations of the tsunami's arrival time will be computed and compared. The choice of the Casablanca area is due to the fact that we dispose of a detailed bathymetry of the region, and then the nonlinear effects can be well considered.

In Fig. 4, we provide a comparison of linear and nonlinear computations of arrival times of a tsunami to a virtual tide gauge station positioned in Casablanca harbor. The result shows that a time difference of $\Delta t=6 \mathrm{~min}$ can be considered to be a good estimate of the error between linear and nonlinear approximations. 


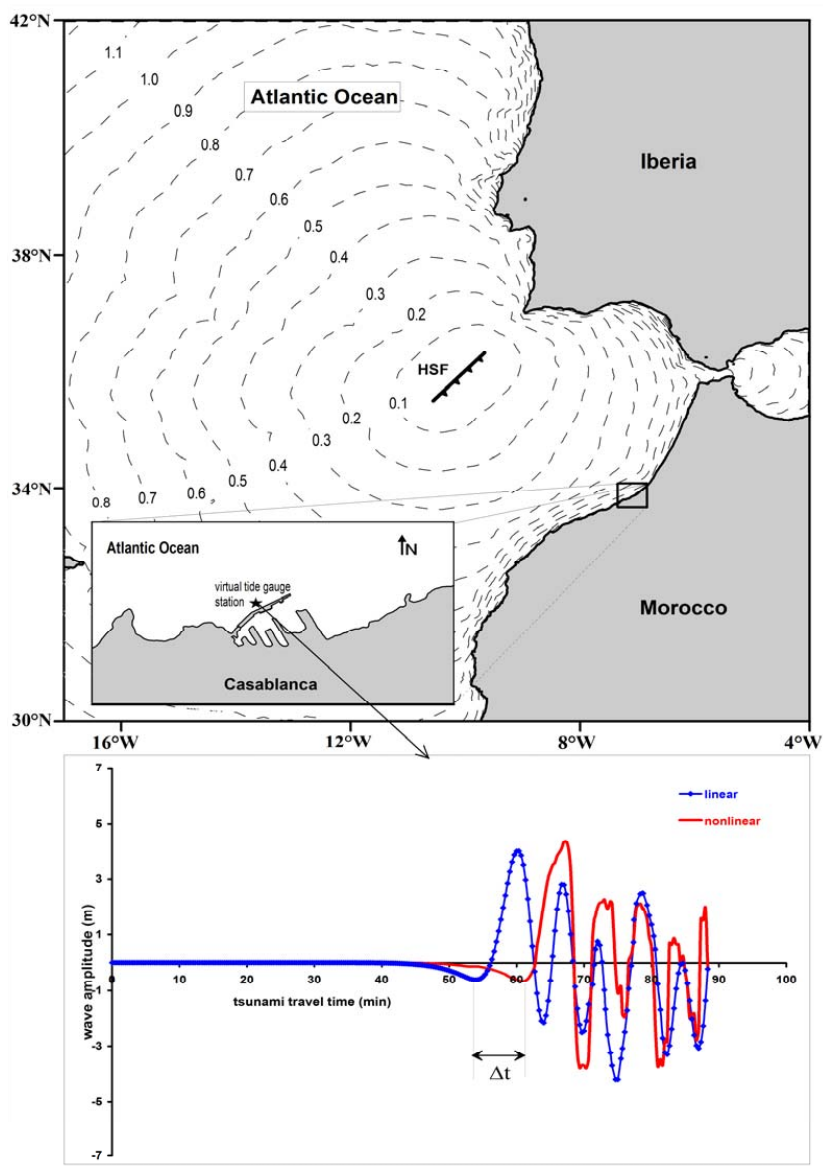

Fig. 4. Tsunami travel time (TTT) map and tsunami travel time error (TTTE) estimation using a comparison of both linear (bleu graph) and nonlinear (red graph) approximations for the HS scenario. The tsunami travel time is in hours $(0.1 \mathrm{~h}$ between two contour curves). $\Delta t$ is the established TTTE for a virtual tide gauge station (black star) located offshore Casablanca-Morocco harbor.

\subsubsection{Seismic detection of tsunamigenic events}

In recent times there has been a significant enhancement of the seismic network coverage around the Azores-Gibraltar fault zone and, in particular, the Cadiz Gulf region. Real time data (latency $<10 \mathrm{~s}$ ) from 35 broadband stations and near real-time data (latency $2 \mathrm{~min}$ ) from 22 additional, enhanced short-period stations are transmitted by VSAT and Internet to the Instituto de Meteorologia Operational Center, which is located in Lisbon. The records are processed in near realtime, making it possible to compute earthquake locations, validated by a human operator, in less than five minutes of the time of origin. One of the major chalenges is to rapidly evaluate the magnitude of large earthquakes ( $\mathrm{Mw}>7)$ using data from regional stations, mostly because the procedures that are commonly used to evaluate magnitudes from short distance records usually underestimate the size of the great earthquakes. However, a recent development (Bormann and
Saul, 2008) makes it possible to compute Mw reliably. Estimating $\mathrm{Mw}$ from $\mathrm{mB}$ magnitudes using broadband records from stations at distances starting from $500 \mathrm{~km}$, it is possible to have hypocentral location and magnitude estimates within the previously mentioned 5 min.

When a tsunamigenic earthquake occurs, the closest coastal areas will be affected by the strong ground-shaking, so that appropriate training and preparedness should trigger an appropriate response by the local authorities and population, mitigating the impact of the tsunami. Ground shaking provides the first warning to the closest coastal areas near 20 min before the tsunami arrival. In the case of an earthquake that is felt locally in a coastal area, but has a magnitude that is lower than the threshold value necessary to generate a tsunami, the TWC will issue a relief message to avoid costly and unnecessary evacuations. For the Northeast Atlantic, the ICG/NEAMTWS 4th session held in Lisbon in 2007 proposed this magnitude threshold to be 5.5 (ICG/NEAMTWS, 2007). If the earthquake magnitude is above the threshold then 5 minutes after the onset of a tsunamigenic earthquake, the TWC will issue a message to advise that a tsunami may have been generated. This message, based only on seismic data analysis, is known to have a low certainty. The tsunami generation must be confirmed by the observation of the tsunami waves with real-time sea-level sensors. When the tsunami has been confirmed, an appropriate message is sent to the civil protection authorities to provide sufficient time in which to take actions to mitigate the impact.

\subsubsection{Tsunami detection and warning time}

The fact that the Gulf of Cadiz is subject to local tsunamis makes the provision of sufficient warning time (WT) a real challenge. Normally, a threatened community is considered warned on a timely basis if the WT is at least $15 \mathrm{~min}$ (IOC-UNESCO, 2005; Henson et al., 2006). Due to the short tsunami travel times in the Gulf of Cadiz, 18-28 min (Fig. 3a-e), to comply with IOC recommendations would mean that the TWS should confirm that a tsunami has been generated only $3 \mathrm{~min}$ after the onset of the earthquake, which is very challenging for the TWS. In this work, we estimate the WT for each scenario, taking into account the time required for the TWS to confirm the tsunami based on measurements of sea-level disturbances. The WT is a function of the tsunami travel time (TTT), delay in sea-level data transmission (Dtr) and delays for tsunami detection (Dd) and confirmation (Dc).

Recently, a comprehensive study on the delays related to tsunami transmission, detection and confirmation was led by Schindelé et al. (2008) for the Western Mediterranean basin. They have considered that $10 \mathrm{~min}$ are needed for the tsunami amplitude measurement and transmission. Their consideration is based upon the fact that the dominant period for earthquake-induced tsunamis is close to $20 \mathrm{~min}$ and 6 to $8 \mathrm{~min}$ is needed to observe the first wave peak. Moreover, 
they assess the Dd considering a network of tsunameters located $50 \mathrm{~km}$ away from the proposed tsunamigenic region and calculate the WT to the different coasts. In the present study, a similar process was used for the Dtr estimation and WT calculation. However, for both Dc and Dd a different approach was adopted, taking into account the specificity of the tsunamigenic potential in the Gulf of Cadiz for the first delay (Dc) and defining a set of Dd-contours that control the WT and the sensors' locations for the second delay.

The Dtr is defined as the time taken to transmit the data from the tsunameter buoy or coastal tide-gauge to the TWC. The Dtr can vary from 2 to 15 min, depending on the transmission system used. The TWS in the Pacific utilizes the GTS (Global Telecommunication System) satellite connection for coastal tide-gauges, which involves a transmission delay of 5 to $15 \mathrm{~min}$ (Schindelé et al., 2008). However, if this delay is short, in comparison to the TTT in the Pacific (several hours), it is considered too long for our case. The Internet connection assures a faster Dtr, of about one to two minutes. However, use of this kind of transmission will be limited in the case of large earthquakes, if the connection has been severely damaged or saturated. The most appropriate transmission system for our case is the Broadband Global Area Network (BGAN). This system, which uses the Inmarsat satellites, offers many advantages, including a short transmission delay $(\leq 2 \mathrm{~min})$ and an independent link to the local telecommunication system. For offshore sensors, a satellite telephone link or radio link is preferred, providing transmission delays that are less than $2 \mathrm{~min}$. In the present study, we will consider a transmission delay of $2 \mathrm{~min}$.

The other delays to be considered in this study concern the time necessary for the detection and confirmation of the tsunami. The first delay, called delay of detection (Dd), is defined as the time necessary for the tsunameter or coastal tide-gauge to detect the tsunami waves after the quake. This delay depends on the sensor position, as well as the TTT, to that position. The second delay, delay of confirmation (Dc), refers to the time required by the operator at the TWC to confirm the generation of the tsunami. Normally, the observation of a quarter of a wavelength is required for the tsunami confirmation. However, due to the MCE scenarios in the Gulf of Cadiz that are relatively large (circa $100 \mathrm{~km}$ in length), the confirmation of the tsunami occurrence can be established well before the observation of the first wave peak; for instance, when the tsunameter records an amplitude value (before the first peak arrival) that exceeds some tenths of centimeters $(\geq 20 \mathrm{~cm}$ ) (see graphs in Fig. 6). The tsunami wave period for the proposed MCE scenarios varies from 4 to $15.5 \mathrm{~min}$ (see graphs in Fig. 6), what implies that about 1 to $3.9 \mathrm{~min}$ are needed to observe the first wave peak. Thus, $5 \mathrm{~min}$ is considered for the Dc.

For sensors in deep water and, close to the tsunamigenic sources, we must consider a protective distance to the fault trace in order to avoid physical damage to the instruments and to permit a separation of the tsunami waves from the seismic waves that are generated by the earthquake. Experience in Japan has shown that appropriate filtering permits the tsunami observation on pressure records that have been disturbed by seismic waves and acoustic reverberations shortly following the onset of the earthquake (H. Mikada, personal communication, 2008). In this work, we consider appropriate a protective distance of $20 \mathrm{~km}$ from the fault traces identified.

An assessment of the Dd-contours will define preliminary zones where tsunamis must be detected and, therefore, zones in which sensors must be positioned. For each scenario, we estimate the appropriate Dd-time-contour according to: (i) safe distance from the quake fault (ii) maximization of WT and (iii) minimization of tsunameters number. To satisfy the previous 3 criteria a 6 min Dd-contour is considered for the CWF, PBF, MPF and HSF scenarios. However, in view of the fact that the tsunami generated by the GBF scenario takes more time to reach the coasts and also radiate small tsunami energy toward the Gulf of Cadiz; and in order to minimize the tsunameters number, a Dd-contour of $10 \mathrm{~min}$ is considered for this scenario.

Once all delays (Dd, Dtr and Dc) are fixed, the following formula (Eq. 1) is used to evaluate the WT to the threatened coastlines:

$\mathrm{WT}=\mathrm{TTT}-(\mathrm{Dd}+\mathrm{Dtr}+\mathrm{Dc})$

where WT is the estimated warning time for a given coastline, TTT is the corresponding tsunami travel time to this coast, and Dd, Dtr and Dc are, respectively, delays of tsunami detection, data transmission and tsunami confirmation for a given configuration of the sea-level observation network.

\section{Sea- level stations network}

\subsection{Coastal tide gauges network}

The role of the coastal tide gauges stations is to confirm the occurrence of a tsunami and assess its impact by collecting sea-level data. This kind of data is only available when the tsunami strikes a coastal point. It can be used to warn other coastal areas where the tsunami takes more time to reach.

The analysis of the performance of the existing coastal tide gauges network in the Gulf of Cadiz region is necessary. To reach the design of the appropriate station locations, coastal sites-specific of major tsunami impact and minimum tsunami travel time must first be established. Tsunami hydrodynamic results are reviewed to assess these sites. From MWH results (Fig. 3a-e), we display a new "global" MWH map, where the maximum values of wave height are extracted along the coastline, taking all scenarios into consideration. The map is computed by using a combination of all $\mathrm{MWH}$-grids in an overlay process inside GIS. A similar process was used to calculate the minimum tsunami travel time to the coastline of the study area and displaying a "global" minimum TTT 


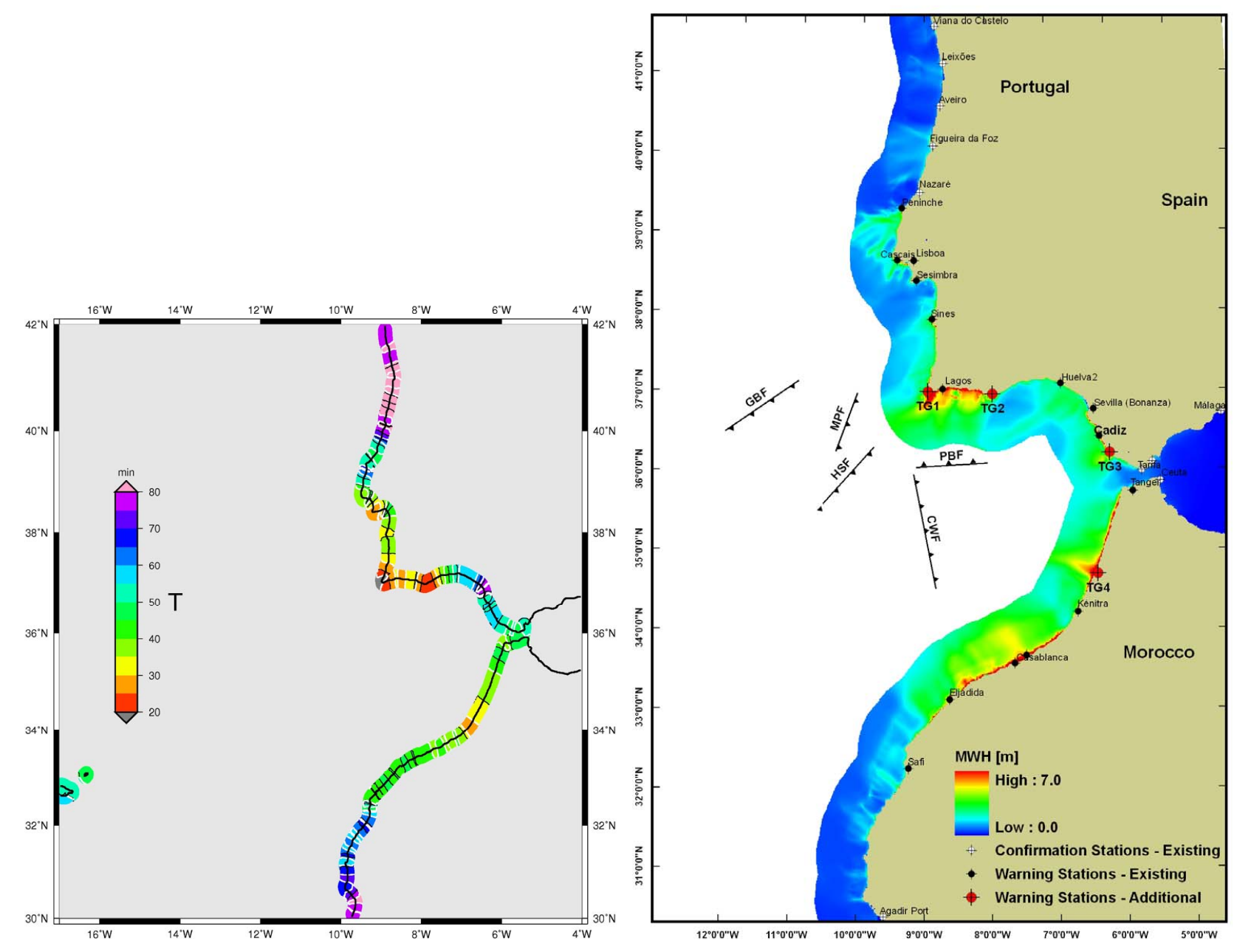

Fig. 5. Maps displaying: (a) minimum tsunami travel time corresponding to the $5 \mathrm{MCE}$ scenarios along the coasts of the study area; (b) MWH along the Gulf of Cadiz coasts considering all the tsunamigenic scenarios, existing and 4 additional tide gauge stations (TG1 to TG4 in red dots) recommended for the region. Two categories in the established tide gauges network are distinguished: warning stations (black dots for existing stations and red dots for additional stations) and confirmation stations (white dots).

map. The maps so established will also help to evaluate the shoreline forecast points in the region. Those points must be evacuated firstly in case of tsunami occurrence.

Figure 5a and $\mathrm{b}$ display respectively the global minimum TTT and MWH maps and gives an initial idea of the specific sites of major impact in the Gulf of Cadiz. Additional tide gauges sites are suggested in the harbors of principal cities and where the wave height is of a maximum value and TTT is minimal. 4 additional stations, (TG1 to TG4), which are presented in Fig. 5b (red dots), are proposed in order to complete the present network. Moreover, two categories in the established tide gauges network, including both existing and additional stations, are distinguished: warning stations and confirmation stations. The first category, which is necessary to detect and monitor tsunamis in the region, regroups the sensors located in the Atlantic coasts between Peininsh and Safi (black and red dots in Fig. 5b). The second category (white dots in Fig. 5b), containing the stations located in the Mediterranean, northern Peininsh and southern Safi, is useful to confirm the tsunami propagation far from the source.

The proposed coastal tide gauges network is sufficiently dense to be capable of measuring any tsunami waves along the study area shoreline. Where possible, this network should be connected to the seismological networks available in the region to provide real-time data transmission. However, in the case of a destructive tsunami event, the tide gauge stations risk to be destroyed by the waves and tsunami data can be lost. The most appropriate way for early tsunami detection is the integration of the real-time deep-ocean network able to detect tsunami waves in deep waters and then to provide greater advance warning more time for evacuation. 


\subsection{Deep-ocean bottom stations (tsunameters) network}

Recent advances in tsunami measurement have provided sensors for deep-ocean assessment and real-time detection of tsunami waves. DART tsunameters (Bernard et al., 2001) used by NOAA in the Pacific warning system acquire and deliver direct and reliable tsunami measurements at deep ocean locations between the source and distant communities. Here, we propose a design for deployment of DART-like sensors in the Gulf of Cadiz.

The Geographical Information system (GIS) is often used for synthesizing, analyzing and handling all kinds of geographical data that describe the Earth. GIS tools available today afford better implementation and integration of spatial data analysis so that optimally suitable sites can be identified or, at least, sites can be rated on their "closeness" to the optimal solution. In this study, GIS is used to optimize the spatial distribution for DART-like sensor locations close to the main seismogenic sources.

Taking in consideration the three defined criteria that control the deployment of tsunameters (Sect. 1.), the GIS-based multi-criteria analysis is used to establish an appropriate, deep-ocean tsunami-detection network that has been adapted to the seismic specificities of the Gulf of Cadiz. The buffer zones defined by the Dd-time-contours (the continuous black contours in Fig. 6), the MWH-grids provided the areas where tsunami waves can be detected and, areas that have a slopes less than about $8^{\circ}$ are combined into a GIS software package (ArcGIS v9.2 - ESRI, 2007) and used as input data. Although the initial data was in a grid-based data structure, most data is deemed suitable for our spatial analysis in a vector-based structure. Thus, the buffer zone boundaries of Dd-contours were converted in a polygon theme and spatially integrated into GIS with all possible earthquake sources digitized in a line theme. Those zones were then overlapped with a buffer zone of $20 \mathrm{~km}$ (the dashed black contours in Fig. 6) width around each source to define the safe distance mentioned in Sect. 3.2.3. Both buffer layers were then intersected spatially, showing all areas respecting our first two criteria and also avoiding those zones in which tsunamis can be detected, offering an acceptable WT (grey zones in Fig. 6). Finally, using the slope map, the flattest areas of the resulting polygons were identified as the best locations for tsunameters. Several possible areas were identified with this analysis, although only three met the criteria boundaries imposed (selected locations represented by white stars in Fig. 6).

Figure 6 presents the installation strategy for tsunameters in the Gulf of Cadiz region. Three DART-like sensors with a spacing of about $110 \mathrm{~km}$ are required to constitute the deepocean tsunami monitoring network. The test of established tsunameters located at distances of $30-60 \mathrm{~km}$ from the earthquake faults (see graphs in Fig. 6), shows the capability of those sensors to detect and measure any candidate tsunami in the region a few minutes after its generation.

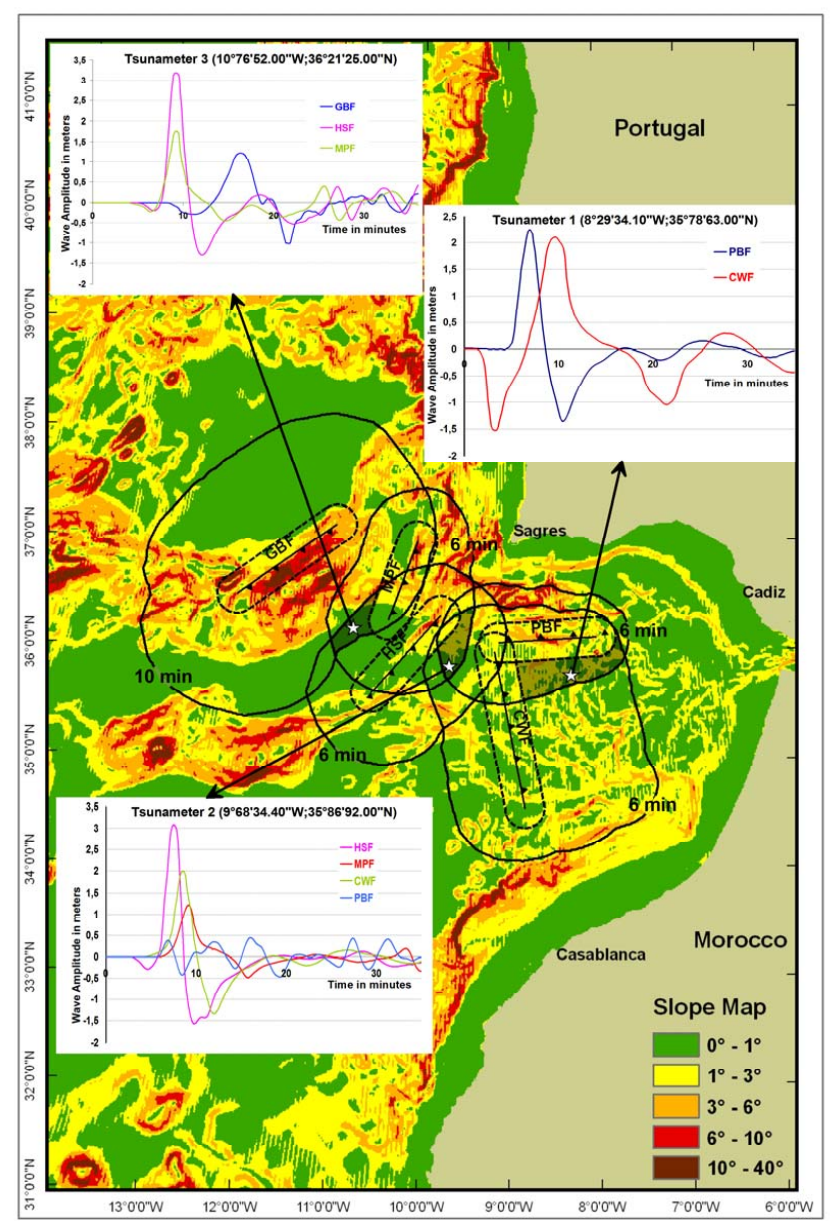

Fig. 6. Established tunameters monitoring network for the Gulf of Cadiz region. White stars are the recommended positions for DART-like sensors in the area. Continuous black lines represent the Dd-time-contours (see Sect. 3.3.3). Dashed black contours around each source define the safe distance of $20 \mathrm{~km}$ (see Sect. 3.2.3). Graphs illustrate waveforms recorded by the proposed DART-like network; only waves detected in the time interval of 0-10 min after the tsunami occurrence are considered. $0-10 \mathrm{~min}$ is considered for tsunami detection in order to maximize the advance warning time.

For the proposed geometry of the sea-level observation network, comprising 3 tsunameters, we use equation no. 1 to compute the warning time (WT); the TTT is extracted from the TTT maps presented in Fig. 3a-e. Table 2 illustrates the Dd-times for each tsunamigenic scenario, the TTT and the WT for different threatened coastal cities in the Gulf of Cadiz. Figure 7 displays the warning time along the coasts of the Gulf of Cadiz area considering all five credible tsunami scenarios and taking into account the established tsunameters network. 
Table 2. Computed TTT to the proposed tsunameters (DART1, DART2 and DART3) and to different points along the Gulf of Cadiz coast. WTs for these coasts are calculated using the equation 1 (Sect. 3.2.3).

\begin{tabular}{|c|c|c|c|c|c|c|c|c|c|c|c|c|}
\hline \multirow[t]{2}{*}{$\begin{array}{l}\text { Tsunami } \\
\text { Scenarios }\end{array}$} & \multicolumn{3}{|c|}{$\begin{array}{l}\text { Dd-time for the } 3 \\
\text { tsunameters }(\mathrm{min})\end{array}$} & \multirow[t]{2}{*}{$\begin{array}{l}\text { Minimum } \\
\text { Dd-time (min) }\end{array}$} & \multicolumn{4}{|c|}{$\begin{array}{l}\text { Tsunami Travel Time } \\
\text { (TTT) }(\mathrm{min})\end{array}$} & \multicolumn{4}{|c|}{$\begin{array}{l}\text { Warning Time } \\
\text { (WT) (min) }\end{array}$} \\
\hline & DART1 & DART2 & DART3 & & Sagres & Lisbon & Cadiz & Casablanca & Sagres & Lisbon & Cadiz & Casablanca \\
\hline GBF & 26.8 & 15.6 & 9.3 & 9.3 & 28 & 29 & 81 & 66 & 11.7 & 12.7 & 64.7 & 49.7 \\
\hline HSF & 13.5 & 2.5 & 5.2 & 2.5 & 24 & 30 & 69 & 48 & 14.5 & 20.5 & 59.5 & 38.5 \\
\hline MPF & 16.7 & 5.4 & 4.0 & 4.0 & 18 & 27 & 70 & 51 & 7.0 & 16.0 & 59.0 & 40.0 \\
\hline PBF & 5.0 & 5.5 & 12.9 & 5.0 & 21 & 36 & 54 & 48 & 9.0 & 24.0 & 42.0 & 36.0 \\
\hline CWF & 1.6 & 4.0 & 12.4 & 1.6 & 24 & 39 & 42 & 36 & 15.4 & 30.4 & 33.4 & 27.4 \\
\hline
\end{tabular}

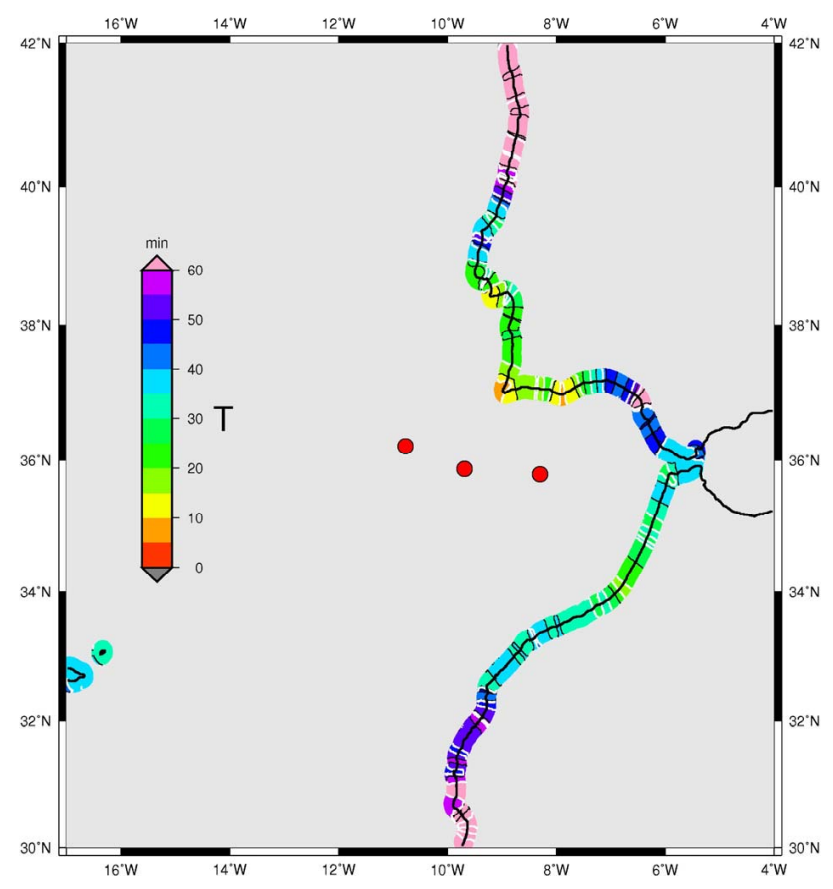

Fig. 7. Warning Time along the coasts in Portugal, Spain and Morocco in the Atlantic (Mediterranean areas were blanked), considering that the 3 DART systems proposed in the paper are available (red dots). All 5 credible tsunami scenarios were considered. The black contours are separated every $5 \mathrm{~min}$ and the white contours every $10 \mathrm{~min}$.

\section{Conclusions and discussions}

The goal of a TWS is to save human lives and mitigate property losses in the case of a tsunami occurrence, and also to confirm the non existence of tsunami waves what avoids to maintain people a long time in higher grounds. Actually, advances in tsunami measurement offer the possibility of detecting tsunami waves in coastal zones, as well as in the deep ocean. Such technology facilitates the construction of any tsunami alert system. This study designs a sea-level tsunami detection network for the Gulf of Cadiz area based on a combination of advances in tsunami measurement, tsunamigenic potential study, numerical modeling and GIS technologies.
3 tsunameter sensors and 29 coastal tide gauges are recommended as the minimum number of stations able to detect tsunamis in the region. The proposed locations provide the greatest possible advance warning for the largest number of threatened coastal communities.

The prediction of the occurrence zones of future tsunamis presents a real challenge when constructing a TWS. The present study summarizes the information gathered by the scientific community in relation to the identification of active tectonic structures in the Gulf of Cadiz. As a result, five earthquake scenarios are envisaged to present the tsunami threat in the region. Their locations are close to the threatened coastlines areas. This makes the region prone to a local tsunami hazard.

The sea level network is recommended to complete the TWS once the tsunamigenic study has been done. The specificity of the tsunamigenic potential in the Gulf of Cadiz led us to choose a specific design for sensors locations. The coastal tide gauge stations are positioned in the harbors of principal cities where tsunami impact is considered major. The emplacement of the sensors and gauges is considered to provide acceptable security and easy installation and maintenance of station. Moreover, this study recommends that 3 DART-like stations should be deployed. Their installation locations have been determined so as to assure a maximum WT, as well as maximum coverage of tsunami potential hazard areas. The approach provides 7.0 to $15.4 \mathrm{~min}$ as a minimum advance warning time for the first threatened coastline. This time may not be sufficient for a global evacuation procedure. This is the reason why awareness campaign and exercises should be implemented in such region, explaining in particular to the inhabitants not to wait official tsunami warning in case of large felt earthquakes, but to immediately move to higher ground or vertically in a concrete building.

The results presented here suffer from inherent limitations due to the models used to describe the earthquake rupture, the tsunami propagation and travel time. In spite of these limitations, the present study corresponds to a first-hand design appropriate to tsunami detection and has important implications for decision makers and land use planning. 
Acknowledgements. This study was funded by the European projects: NEAREST under the contract 037110, and TRANSFER under the contract 37058. The authors thank H. Mikada for comments on the earthquake and tsunami signal detection. Finally, we wish to thank F. Schindelé and another anonymous reviewer for their valuable and constructive comments.

Edited by: S. Tinti

Reviewed by: F. Schindelé and another anonymous referee

\section{References}

Aki, K.: Earthquake mechanism, Tectonophysics, 13(1-4), 423432, 1966

ArcGIS v9.2 - ESRI: Environmental Systems Research Institute, ArcGIS 9.2, Desktop Help [online] available at: http://webhelp. esri.com/arcgisdesktop/9.2/index.cfm?TopicName=welcome, 2007.

Baptista, M. A., Heitor, S., Miranda, J. M., Miranda, P., and Mendes-Victor, L.: The 1755 Lisbon tsunami; evaluation of the tsunami parameters, J. Geodynamics, 25, 143-157, 1998a.

Baptista, M. A. and Miranda, J. M.: Revision of the Portuguese catalog of tsunamis, Nat. Hazards Earth Syst. Sci., 9, 25-42, 2009, http://www.nat-hazards-earth-syst-sci.net/9/25/2009/.

Baptista, M. A., Miranda, J. M., Chiericci, F., and Zitellini, N.: New Study of the 1755 Earthquake Source Based on Multi-channel Seismic Survey Data and Tsunami Modeling, Nat. Hazards Earth Syst. Sci., 3, 333-340, 2003,

http://www.nat-hazards-earth-syst-sci.net/3/333/2003/.

Baptista, M. A., Miranda, P. M. A., and Mendes Victor, L.: Maximum Entropy Analysis of Portuguese Tsunami: The Tsunamis of 28/02/1969 and 26/04/1975, Sci. Tsunami Hazards, 10(1), 9-20, 1992.

Baptista, M. A., Miranda, P. M. A., Miranda, J. M., and MendesVictor, L.: Constrains on the source of the 1755 Lisbon tsunami from numerical modelling of historical data on the source of the 1755 Lisbon tsunami, J. Geodynamics, 25, 159-174, 1998b.

Bernard, E. N., Gonzalez, F. I., and Meing, C.: Early detection and real-time reporting of deep-ocean tsunamis. International Tsunami Symposium 2001, 7-10 August 2001, Seattle, Washington, 2001.

Bermann, P. and Saul, J.: The new IASPEL standard broadband magnitude mB, Seism. Res. Lett., 79(5), 698-706, 2008.

Geist, E. L. and Dmowska, R.: Local tsunamis and distributed slip at the source, Pure Appl. Geophys., 154, 485-512, 1999.

Gjevik, B., Pedersen, G., Dybesland, E., Harbitz C. B., Miranda, P. M. A., Baptista, M. A., Mendes-Victor, L., Heinrich, P., Roche, R., and Guesima, M.: Modelling tsunamis from earthquake sources near Gorringe Bank southwest of Portugal, J. Geophys. Res., 102(C13), 27931-27949, 1997.

Gonzalez, F. I., Bernard, E. N., Meinig, C., Eble, M. C., Mofjeld, H. O., and Stalin S.: The NTHMP Tsunameter Network, Nat. Hazards, 35, 25-39, 2005.

Gràcia, E., Dañobeita, J., Vergés, J., and the PARSIFAL team: Mapping active faults offshore Portugal $\left(36^{\circ} \mathrm{N}-38^{\circ} \mathrm{N}\right)$ : implications for seismic hazard assessment along the southwest Iberia margin, Geology, 31, 83-86, 2003.

Gutscher, M.-A., Malod, J., Rehault, J.-P., Contruci, I., Klingelhoefer, F., Mendes-Victor, L., and Spakman, W.: Evidence for ac- tive subduction beneath Gibraltar, Geology, 30(12), 1071-1074, 2002.

Gutscher, M.-A., Baptista, M.A., and Miranda, J.M.: The Gibraltar Arc seismogenic zone (part 2): constraints on a shallow east dipping fault plane source for the 1755 Lisbon earthquake provided by tsunami modelling and seismic intensity, Tectonophysics, doi:10.1016/j.tecto.2006.02.025, 2006.

Heinrich, P., Baptista, M. A., and Miranda, P.: Numerical simulations of the 1969 tsunami along the Portuguese coasts. Preliminary Results, Sc. Tsunami Hazards, 12(1), 3-25, 1994.

Henson, J. I., Muller-Karger, F., Wilson, D., Morey, S., Maul, A. G., Luther, M., and Kranenberg, C.: Strategy geographic positioning of sea level gauges to aid in early detection of tsunami in the intra-American sea, Sci. Tsunami Hazards, 3(25), 173-207, 2006.

ICG/NEAMTWS: Intergovernmental Coordination Group for the Tsunami Early Warning and Mitigation System in the North Eastern Atlantic, the Mediterranean and Connected Seas, Oceanographic Commission, Reports of Governing and Major Subsidiary Bodies, UNESCO, 4th Session, Lisbon, Portugal, 2007.

IOC-UNESCO: An Intra Americas Sea Tsunami Warning System Project Proposal, edited, UNESCO Intergovernmental Oceanographic Commission, 2005.

Iribarren, L., Vergés, J., Camurri, F., Fullea, J., and Fernàndez, M.: The structure of the Atlantic-Mediterranean transition zone from the Alboran Sea to the Horseshoe Abyssal plain (Iberia-Africa Plate Boundary), Marine Geology, 243, 97-119, 2007.

Johnston, A.: Seismic moment assessment of earthquakes in stable continental regions - III. New Madrid, 1811-1812, Charleston 1886 and Lisbon 1755, Geophys. J. Int., 126, 314-344, 1996.

Kanamori, H. and Anderson, D.L.: Importance of physical dispersion in surface-wave and free oscillation problems - review, Rev. Geophys., 15(1), 105-112, 1977.

Liu, P. and Cho, Y.-S.: An integral equation model for wave propagation with bottom friction, Journal of Waterways, Port, Coastal, and Ocean Engineers, 120, 594-608, 1994.

Liu, P. L.-F., Cho, Y.-S., Briggs, M. J., Synolakis, C. E., and Kanoglu, U.: Run-up of Solitary Waves on a Circular Island, J. Fluid Mech., 302, 259-285, 1995.

Liu, P. L.-F., Woo, S.-B., and Cho, Y.-S.: Computer programs for tsunami propagation and inundation, Technical report, Cornell University, 1998.

Mansinha, L. and Smylie, D. E.: The Displacement Field of Inclined Faults, Bull. Seismol. Soc. Am., 61(5), 1433-1440, 1971.

Matias, L. M., Ribeiro, A., Baptista, M. A., Zitellini, N., Cabral, J., Terrinha, P., Teves Costa., P., and Miranda, J. M.: Comment on: Lisbon 1755: A case of triggered onshore rupture?, edited by: Vilanova, S. P., Nunes, C. F., and Fonseca, J. F. B. D, B. Seismol. Soc. Am., 95(6), 2534-2538, doi:10.1785/0120040023, 2005.

Medialdea, T., Vegas, R., Somoza, L., Vázquez, J. T., Maldonado, A., Díaz-Del-Río, V., Maestro, A., Córdoba, D., and FernándezPuga, M. C.: Structure and evolution of the "Olistostrome" complex of the Gibraltar Arc in the Gulf Of Cadiz (Eastern Central Atlantic): Evidence from two long seismic cross-sections, Mar. Geology, 209, 173-198, 2004.

Okada, Y.: Surface deformation due to shear and tensile faults in a half-space, B. Seism. Seismol. Am., 75(4), 1135-1154, 1985.

Scholz, C. H.: Scaling laws for large earthquakes: consequences for 
physical models, B. Seismol. Soc. Am., 72, 1-14, 1982.

Schindelé, F., Loevenbruck, A., and Hébert, H.: Strategy to design the sea monitoring networks for small tsunamigenic oceanic basins: the Western Mediterranean case, Nat. Hazards Earth Syst. Sci., 8, 1019-1027, 2008,

http://www.nat-hazards-earth-syst-sci.net/8/1019/2008/.

Stich, D., Mancilla, F. L., and Morales, J.: Crust-mantle coupling in the Gulf of Cadiz (SW-Iberia), Geophys. Res. Lett., 32, L13306, doi:10.1029/2005GL023098, 2005.

Titov, V. V., Mofjeld, H. O., Gonzalez, F. I., and Newman, J. C.: Offshore forecasting of Alaska-Aleutian subduction zone tsunamis in Hawaii, NOAA Technical Memorandum, ERL PMEL-114, Seattle, Washington, 22 pp., 1999.
Zitellini, N., Gràcia, E., Matias, L. M., Terrinha, P., Abreu, A. M, DeAlteriis, G., Henriet, J-P., Dañobeitia, J., Masson, D. G., Mulder, T., Ramella, R., Somoza L., and Diez, S.: The Quest for the Africa-Eurasia plate boundary west of the Strait of Gibraltar, Earth Planet. Sci. Lett., 280(1-4), 13-50, 2009.

Zitellini, N., Chierici, F., Sartori, R., and Torelli, L.: The tectonic source of the 1755 Lisbon Earthquake, Annali di Geofisica, 42(1), 49-55, 1999.

Zühlke, R., Bouaouda, M.-S., Ouajhain, B., Bechstädt, T., and Leinfelder, L.: Quantitative Meso-Cenozoic Development Of The Eastern Central Atlantic Continental Shelf, Western High Atlas, Morocco, Mar. Pet. Geol., 21, 225-276, 2004. 